\title{
Towards Post-Comparative Philosophy
}

\author{
Interview with Ralph WEBER* by Nevad KAHTERAN**
}

Ralph Weber was born to Swiss parents in 1974 in Johannesburg, South Africa. He studied Staatswissenschaften (politics, economics and law) at the University of St. Gallen and at the Graduate Institute of International and Development Studies in Geneva. He then went on to study at the University of Hawai'i in Manoa and the University of Peking. He obtained his $\mathrm{PhD}$ in 2007 at the University of St. Gallen, and for a decade taught the history of political ideas and political theory there. Between 2008 and 2014, Weber was employed as post-doctoral researcher and senior researcher and lecturer at the University Research Priority Program "Asia and Europe" at the University of Zurich. In December 2014, Weber began his work as an Assistant Professor at the Institute for European Global Studies of the University of Basel. In 2016, he successfully completed his habilitation in Philosophy (venia legendi: comparative philosophy) at the University of Zurich. At the University of Basel, he holds full examination and promotion rights in Political Science, Philosophy, and European Global Studies, and in 2020 was promoted to Associate Professor. He has been the book review editor (Europe) for Philosophy East and West and since 2017 the President of the European Association for Chinese Philosophy (EACP).

Dear Ralph, according to your CV, your interests can be summarized in these three fields:

Comparative philosophy and questions concerning philosophy of comparison, as well as programmatic suggestions of a post-comparative philosophy;

Chinese philosophy, i.e. classic and modern Confucianism, particularly the sociological and political aspects, current political philosophy of the People's Republic of China and contemporary Chinese politics; and

* Ralph WEBER, Professor for European Global Studies / Director of the MA and PhD Programs in European Global Studies, Institute for European Global Studies, University of Basel.

Email address: ralph.weber@unibas.ch

** Nevad KAHTERAN, Professor of Eastern and Comparative Philosophy at the University of Sarajevo.

Email address: nevad.kahteran@ff.unsa.ba

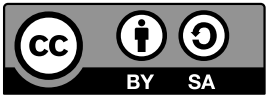


Global political theory and the history of ideas, theoretical and practical questions of text interpretation as well as conceptual and methodological aspects of cross-linguistic and cross-cultural research, including discussions around Eurocentrism, area studies, and European global studies.

Let us start our conversation with the name for your research area, "Politics and Philosophy in European Global Knowledge Production", which focuses on Europe and its role in global knowledge production, straddling across the disciplines of Philosophy, Political Science and European Global Studies with its five research topics. Can you tell us a bit more about this, and what holds it together as a research focus?

Ralph Weber: Sure. Knowledge production is a key factor in our contemporary world. Its workings, promises and problems are intimately related to the pertaining social, economic and political conditions. The tension between philosophy, which fashions itself as being exclusively about knowledge, and politics, which understands knowledge at best as one goal among many and at worst consciously instrumentalizes it, is age-old. Today, in a time when historical legacies meet new global realities, the conditions and possibilities for knowledge production have become increasingly complex and entangled. The five research topics that I currently pursue are 1. Comparison and Comparative Philosophy; 2. European Studies from a Global Perspective; 3. European Global Studies: Concepts, Methods, and Aims; 4. Global History of Political Thought; and 5. Chinese Politics (BRI, China's Sharp Power and influence operations, Swiss-Chinese Relations). At first glance, these might look like quite disparate topics, but in my mind they add up quite consistently and build around the key idea of European Global Studies. This is of course not about making the global an extension of the European. It advocates a relational approach to Europe, which is a concept so elusive and contingent that it escapes in my view any attempt to fix it in a philosophical idea, as some previous philosophers have tried to fixate it. This relationality also explains why someone like me, who has research interests in "Africa" and "Asia", particularly "China", feels completely at home at an institute that has "Europe" in its name. The point is more about understanding how different actors and institutions make conceptual use of "European"/"non-European" and similar concepts, and how these politics inform our own knowledge claims when we, for instance, engage in philosophical argument or define disciplines in academia. One underlying problematic of all this is the problem of Eurocentrism, which is a topic that I've been teaching for several years and which continues to be high on my research agenda. Together with colleagues from Zurich, Edinburgh and Basel, we just launched a four-year research project, funded by the Swiss National Science Foundation, on the topic of "Reversing the Gaze: Towards Post-Comparative Area Studies”, which has quite a few interlinkages with my work in comparative philosophy, but is bringing together a variety of disciplines. 
Comparative Philosophy without Borders (written together with Arindam Chakrabarti, currently at Stony Brook University in New York) speaks about four phases of Comparative Philosophy in a Pluralistic World. According to your best insights and knowledge, in which phase are we right now?

Ralph Weber: We divide the history of comparative philosophy into roughly three phases and advocate that we are indeed at the beginning of a new, a fourth phase, or at least that this is where we should be. We talk of stages rather than phases, since one phase has not simply replaced an earlier one such as in a palimpsest, but instead like stages building on each other they continue to co-exist in parallel and crisscrossing fashion. Let me just recall the three stages first, as we lay them out in the book. These are really just more caricatures than solid historical accounts, but they are supposed to bring out a contrast of basic ideas in terms of universalism, localism, and their critical conjuncture.

The imperative at the first stage amounted to something like modern Western philosophy has sophisticated debates about, say, freedom of the will, so let's find something similar in Indian or African philosophy. This exercise resulted in statements such as "we/they had something similar (but something which had to be looked for, retrieved)." Similar to the idea of strategic essentialism, some might have pursued a more strategic motivation in finding various resemblances, overlaps, and anticipations, namely to draw attention to non-Western traditions in the first place. It was thus happily and often apologetically claimed that Chinese thinkers also had philosophy and ethics in the Greek sense, that there was also logic and phenomenology in India! More boldly (with the arrogance of cultural insecurity), some asserted that "we said all of that long ago", and "we said it much better long before you". The basic idea at this stage is universalism.

At the second stage of comparative philosophy, the impetus was more to find contrasts and context-dependent culture-immanent peculiarities in non-Western philosophies, and to detect specific lacks compared to the Western tradition. The resulting lack-discourse ran a gamut of asserting that there was no possibility, no propositions, no deductive validity, no free will or a priori in Indian philosophy, no ontology, no logic and no truth claims in Chinese philosophy, no formal logic in African philosophy, and so on and so forth, or simply no philosophy at all. The moderate version drew the conclusion that these missing elements had to be introduced and adapted into Indian, Chinese or African philosophy. A more strident version of the second stage had it that these philosophies, if they were to retain their unique character, are better off without this Western theoretical stuff. Indian philosophy can easily do without the idea of "possible worlds", which shows that it is far from being a necessary or compelling topic to discuss. It thus 
became an intellectual option to assert with confidence the lack of this or that, that there was no notion of correspondence truth or a creator God transcending the empirical world in Chinese philosophy, and no subject-object dichotomy in Latin American philosophy. That was in fact thus not even a lack, but a major strength. The implication was that Western philosophy should question these notions because there could be such rich traditions eschewing them altogether. The basic idea here is localism.

The third stage comprises some of the best comparative philosophy written today, that is, at the critical conjuncture between universalism and localism. The imperative is to re-interpret Indian, Chinese, or Japanese philosophy in terms of Western philosophical ideas as much as contributing to English-language philosophy by bringing in elements of Asian or African or Hawaiian philosophy. Such crisscrossing comparative philosophy harks back to the regional or intra-traditional philosophical traditions, the Western analytic, the Continental phenomenological, the Indian analytic, the Indian sociocultural, the Asian literary, the Feminist European, the historical-political, the literary aesthetic, and enriches them with the lessons of comparison. In this sense, we are approaching a more level and global epistemic playing field, and I would understand much of this in the context of the postcolonial and decolonial critiques of Eurocentrism at the intellectual level, as well as the increased connectivity at the practical level, including the new digital and technological possibilities that have changed our ways of communication and invalidated previous excuses for non-communication. Against this background, there is an immense space to be filled with studies and research deploying a more global vocabulary and trying the cross-cultural enterprise the other way. Importantly, however, many such attempts directly or indirectly remain tied to a comparative setting that operates with notions such as "Chinese", "European", "Japanese", "Islamic" philosophy, and so on.

This is where we stand today. Now, in our book, Comparative Philosophy without Borders, Arindam Chakrabarti and I wanted to put a spin on the practice of comparative philosophy at the third, current stage, which eventually might lead us to a fourth stage. The spin would take us beyond comparative philosophy to what I prefer to call "post-comparative" philosophy, but others, who work towards similar ends like, for example, Jonardon Ganeri, call by various different names. It would amount to just doing philosophy as one thinks fit for getting to the truth about an issue or set of issues, by appropriating elements from all philosophical views and traditions one knows of but making no claim of "correct exposition", and instead just addressing hitherto unsolved problems and possibly raising issues that have never been considered before, anywhere. The crucial point is one about epistemic authority. An argument is not persuasive because 
it is one made, say, from within Indian philosophy, but it is persuasive because it is a good argument.

In this fourth stage, comparative philosophy can become truly borderless and eventually drop its epithet "comparative", although one should anticipate strong resistance against this last phase of dropping the qualifier. Good creative philosophy in a globalized world should spontaneously straddle geographical areas, languages and cultures, temperaments and time-periods (mixing classical, medieval, modern, and postmodern), styles and subdisciplines of philosophy, as well as mix methods, sprinkling phenomenology, and political economic analysis into analytic logicolinguistic or hermeneutic, or culture studies or literary or narrative methods-whatever comes handy. The result would be either very flaky mishmash or first-rate original work. Philosophers, especially those who strive for clarity and truth, have to live with more confusion than clear and distinct ideas, when they welcome fusion philosophy as their preferred genre.

There is a double movement required for a global post-comparative philosophy along these lines. On the one hand, comparative philosophy should simply be philosophy or, as we say in our book, "just philosophy", in both senses of the term "just", but with the distinguishing characteristic of being informed by a more global outlook, of which a variety of styles and conceptualizations is and probably should be advocated. This should not imply, in my view, the more radical stance that all philosophy must be such and only such philosophy. I still find it perfectly legitimate for a philosopher to study with, against and beyond Wittgenstein for all his or her professional career, or to work at the exciting space opened up between analytic philosophy and cognitive science, etc. What it implies is a normalization, say, to start an essay on Wittgenstein not with a contrasting reference to Plato, but to Al-Farabi, Dharmakīrti or Gloria Anzaldúa, that is, approaching Wittgenstein from a different positionality, or to work on the space between analytic philosophy and cognitive science by including arguments derived from Tibetan Buddhism. On the other hand, philosophy - regardless of whether comparative, post-comparative or decidedly not either-must find ways to connect to other disciplines in productive ways. Just as such connections exist with cognitive science or linguistics, it is imperative for philosophy, say, to introduce more upto-date historiographical approaches when writing the history of philosophy, or to study how the meso-level of philosophical institutions interrelates with philosophical debates, thus establishing a sociology of philosophy within philosophy departments. Added to this is the question of interdisciplinarity, transdisciplinarity, or, as my colleague in Basel, the global historian Madeleine Herren-Oesch, among others, proposes, post-interdisciplinarity, which I understand as an attempt to move beyond the often fruitless and poorly informed controversies of 
disciplinarity versus interdisciplinarity. In other words, philosophy understood as a distinct but global discipline and a self-critical enterprise, that is aware of its own contingencies, the power-knowledge nexus, and new global realities, should not only be progressive by finding common ground with cognitive science and some select natural sciences, but also by redefining its relationship to disciplines in the Humanities and Social Sciences and epistemic formations beyond disciplinarity, and by updating its own ways of how to do philosophy in line with new digital and technological possibilities. This is really a point about diversifying philosophy, including current comparative philosophy, precisely in order to ensure its own attractive and distinct identity.

The need for a philosophy of comparison suggested in your opus poses a series of intriguing and intricate questions, comparing what with what, and in what respect? What "philosophy" is comparative philosophy comparing? And especially "bow to compare?", or rather can you say a little more on the question of the methodological state of Comparative Philosophy?

Ralph Weber: Comparison is still a puzzle to me in many ways. I began with a static and I would think quite consensual view of comparison, which analytically distinguishes four aspects of comparison: 1) A comparison is always made by someone; 2) At least two relata (comparata) are compared; 3) The comparata are compared in some respect (tertium comparationis); and 4) The result of a comparison is a relation between the comparata in view of the respect chosen. Obviously, much hinges on the comparer, who for some reason or another has come to believe that, although everything is somehow comparable with everything else, the chosen comparata are particularly worthy of "being thrown together side by side" ( $\pi \alpha \rho \alpha \beta \alpha \dot{\alpha} \lambda \lambda \varepsilon v)$, i.e. that they ought to be compared. I have claimed that it is useful to distinguish a fifth aspect that needs to be located in the above, roughly chronological characterisation of comparison between the first and second aspects: 5 . The two (or more) comparata share a pre-comparative tertium, constituted by at least one commonality (i.e. being chosen for comparison by the comparer) and usually by many more commonalities (tertia). Crucially, most of these commonalities are already well established (even if only vaguely, implicitly known to the comparer, who is perhaps also unaware of them) before the comparer sets out to compare them. These commonalities inform the decision to compare and have a huge, but little-understood impact on the concrete respects for which one then sets out to compare whatever one compares. Of course, this touches on a whole lot of hermeneutical issues.

In light of this insight, I have then shifted my attention toward a more dynamic view of comparison, trying to understand what happens when we compare in 
terms of the objects of comparison. At this juncture, I introduced another distinction. Before, I indiscriminately referred to comparata, but a finer distinction has comparanda on the one side (that which the comparer sets out to compare), and refers to that which is and comes to have been compared in the course of the comparison as comparata instead. In light of this distinction, the pre-comparative tertium emerges as a privileged vantage point from which to carry out analyses of comparisons. This gives us an opportunity with regard to the comparer (inasmuch as there is any such opportunity) to uncover the reasons and purposes attached to the comparison and to reconstruct some of the presuppositions that guided the comparer's understanding of the comparanda merely based on the given text that contains the comparison. That a comparer has compared two (or more) comparata without having any presupposition whatsoever that has led them to choose these comparanda, and not others, is a rare case, if it is possible at all. In academic comparison, where the universe of cases is always in one or another way predefined, we can safely rule out the existence of such a case. This means to the extent that the choice of comparanda is not random and motivated by asserted commonalities (beyond the one commonality of each being a comparandum), knowledge of these commonalities is in itself the result of prior comparison. For how else can you come to hold that two objects (or events, or anything else) share a commonality, if you have not put them next to one another and compared them with the aim of discovering a relation of commonality between them?

From a broader perspective, the pre-comparative tertia of a given comparison are often drawn from earlier comparisons (they are in this sense post-comparative), while the given comparison will necessarily produce new post-comparative tertia (perhaps in turn used in later comparisons as pre-comparative tertia). Thus emerges a dynamic network of a great chain of comparisons. As important as it is to understand this inevitable broader context in a given case of comparison, it is also pertinent to understand the exact workings of the case at hand as much as possible. The distinctions between comparanda and comparata as well as the pre-comparative tertium, the tertium comparationis and the post-comparative tertium offer an analytically refined take on an artificially isolated given case of a single comparison. However, examined more closely, it is found to contain just another chain and complex structure of comparisons which informs the resulting relation of the overall comparison. The proposed vocabulary helps highlight (and analyse) the inner dynamic of a given case of comparison, as advanced in the many scholarly articles or research projects announcing a comparative study in their titles, but also in more hidden comparative settings.

The inner dynamic in a chosen case of comparison marks an important gap that any comparative inquiry is bound to produce. When choosing to compare two 
comparanda, the comparer has some presupposition or presumed knowledge of what the comparanda are. When then comparing them in each other's light, the comparer inevitably through this very effort acquires new knowledge about the comparanda, i.e. knowledge that he or she could not possibly have possessed before the comparison. This is the gap between what the comparanda and the compara$t a$ are in the understanding or knowledge of the comparer. Still, distinguishing between comparanda and comparata should not mislead us into thinking that the two are clearly distinct. In the process of comparison, comparanda are being transformed into comparata. The two terms demarcate an analytic distinction for two different stages in that transformation. But obviously, and without going into the intricate metaphysical problems of the nature of change, alteration, and transformation, the claim must be that the resulting comparata are still in an important way the same as the initial comparanda. In one sense, but not in another, for they are the same and they are different. If they were not the same in any sense, merely different, then the comparison would not have been what it was supposed (and perhaps announced) to be about. Were they the same and no different, then no inquiry and no comparison would have taken place.

Against this static and dynamic understanding of comparison, I have then delved into some specific questions, like the role of generalization, vagueness, the relation between comparison and analogy, the presumed problem of one-sidedness (which is not simply hermeneutical pre-judgement), the standard but in my view confused expression of comparison being about "similarities and differences", etc. All of this I found very rewarding, but, if anything, it increased my sense of puzzlement. One aspect that I was becoming very interested in concerns the fourth aspect in the static conception of comparison, namely the result of a comparison, which is conventionally understood as "a relation" between the comparanda "in view of the respect chosen". Actually, reading this carefully would bring one already to the conclusion that the result of a comparison is a relational relation, one in terms of the two comparanda and another one in terms of the respect in which the comparison has been done.

I linked this to a closer examination of the tertium comparationis (the respect) as located on a ladder of abstraction (an idea that I later learned Giovanni Sartori had worked on long ago in comparative politics), with maximal particularity at the one end and maximal abstraction at the other end. The level of abstraction chosen directly determines whether something in the end comes to be viewed as a commonality or a difference. This insight was a revelation for me. It helped me better understand what happens in academic group discussions, how disagreement more often than not is about the appropriate level of abstraction (specialists for obvious reasons tend to resist abstraction, while comparatists depend on 
it), and how the perceived danger of one-sided comparison to some extent relies on a mistaken view of comparison, confusing singularity with particularity. Being as clear and precise as possible about the chosen level of abstraction for one's tertium comparationis is absolutely crucial for informed comparative discussions. Without it, what is claimed as a difference literally could also be a commonality. It is this sort of issue that has led me to believe that we really still do not quite know what we do when we compare things. Discussions across disciplines and comparative approaches (including law, theology or religious studies) are really important (political science, for instance, is great on selection bias, theology in turn on incomparability) and I am glad that Mark van Hoecke and Maurice Adams are editing a soon to be published volume (with Edward Elgar) exactly in this spirit.

Obviously, Comparative Philosophy has had its problems for decades and it has to be replaced with a more suitable approach, and I can agree with some of our mutual colleagues like Jana Roskker that the notion (and the methods) of comparative philosophy are outdated in the present forms. I have on my mind her new book that has been accepted for publication at Bloomsbury next year: Interpreting Chinese Philosophy: A New Methodology. Which one will be more convenient for you: Comparative or Post-Comparative, Cross-Tradition engagement in philosophy, Cross-Cultural Philosophy, Fusion Philosophy having on my mind Robert E. Allinson's contributing article ("The Myth of Comparative Philosophy or the Comparative Philosophy Malgré Lui") to Bo Mou's edited volume Two Roads to Wisdom?-Chinese and Analytic Philosophical Tradition (Open Court, 2001), as well as your own work that you co-edited with Arindam Chakrabarti, Comparative Philosophy without Borders (Bloomsbury Academic, 2015)?

Ralph Weber: Of course, I have some personal preferences for my own approach, but I would not want everyone to accept and adopt it. That would not be helpful. I love seeing a kind of flourishing methodological pluralism, and I'm currently busy putting together an edited volume with Robert Smid and Steven Burik, featuring and discussing very different methodological approaches to comparative philosophy (forthcoming with Bloomsbury Academic). And I'd want to reserve the right for myself to use different approaches in different projects. Still, methodological pluralism might sometimes mean as little as that everyone does whatever they want, and method is then looked upon as of less importance. This is not my view. I think we need a healthy and vigorous discussion on method that necessarily and rightly remains inconclusive, and we also need more discussion on methodological pluralism at the meta-level. I have just finished a book manuscript with Martin Beckstein on this, regarding questions of interpretation in political theory (forthcoming with Routledge). 
Personally, I have taken great joy in reading early Enlightenment philosophers who tackled the question of how to reconcile dogmatism with scepticism some three hundred years ago. They opted for eclecticism. Their point was not to create a third position, but rather to adopt a philosophical attitude that allowed combining the virtues of these philosophical traditions. Meant to serve as a "permanent makeshift solution" (Schneiders), philosophical eclecticism can be characterized as a meta-theoretical disposition vis-à-vis philosophical positions. Following scepticism, eclecticists stressed the importance of doubt. In contrast to Descartes, however, the dubitatio eclectic, as e.g. articulated by Christian Thomasius, aimed at questioning prejudices selectively and successively, rather than systematicallyand remained committed to the quest for truth.

Eclecticism involves a self-critical disposition. It manifests itself in a commitment to fallibilism, which Thomasius expressed as sticking to his eclectically derived truths only "until somebody else disabuses myself from misconception." Finally, the critical/self-critical selection of elements from philosophical positions is guided by the libertas philosophandi. In other words, the eclecticist's work does not limit itself to a thoughtless combination of other people's thoughts, but takes the liberty to balance, interpret and appropriate them for the purpose of original philosophical construction. The eclectic conciliatio is not a harmonizing operation that marginalizes difference. On the contrary, mediation requires recognition of distinctness.

To eclecticism, I would add pragmatism. The work of early Enlightenment eclecticists included proto-pragmatist ideas. They were perceptive of the need to adapt ideas to the changing circumstances. Thomasius even likened truth to the useful, and the useful in turn to that which promotes welfare. Yet American pragmatism, as especially associated with the work of William James, more consequently encourages us to grasp theories or approaches as tools to make conscious, selective use of for our specific research projects. American pragmatism thus productively adds to philosophical eclecticism. And it is well-suited for a conceptual marriage because, like philosophical eclecticism, it is a meta-theoretical posture rather than a substantial standpoint, because it cultivates a like-minded distance to both dogmatism and scepticism and is equally committed to fallibilism (John Dewey). The Italian philosopher Giovanni Papini has given us the metaphor that most aptly captures the kind of methodological pluralism that a pragmatist eclecticism would advocate. As quoted by William James:

(Pragmatism) lies in the midst of our theories, like a corridor in a hotel. Innumerable chambers open out of it. In one you may find a man writing an atheistic volume; in the next someone on his knees praying for faith 
and strength; in a third a chemist investigating a body's properties. In a fourth a system of idealistic metaphysics is being excogitated; in a fifth the impossibility of metaphysics is being shown. But they all own the corridor, and all must pass through it if they want a practicable way of getting into or out of their respective rooms.

This is how I would like to see practitioners of (post-)comparative philosophy pursue their projects in different rooms, but come together in the corridor where philosophy would also meet politics, economy, and so much more-a meeting that those philosophers would have to endure and successfully pass before they could claim more social relevancy beyond their own discipline. 